\title{
The non-random structure of multi-trophic ecological inter- actions maximizes species coexistence within ecologically re- alistic constraints
}

\author{
David García-Callejas ${ }^{1,2,}$, Oscar Godoy ${ }^{2}$, Lisa Buche ${ }^{2}$, María Hurtado ${ }^{1,2}$, Jose B. Lanuza ${ }^{1,3}$, \\ Alfonso Allen-Perkins ${ }^{1,4}$, and Ignasi Bartomeus ${ }^{1}$ \\ ${ }^{1}$ Estación Biológica de Doñana (EBD-CSIC), Seville, Spain. \\ ${ }^{2}$ Departamento de Biología, Instituto Universitario de Ciencias del Mar (INMAR),Universidad de Cádiz, E-11510, Puerto \\ Real, Spain. \\ ${ }^{3}$ School of Environmental and Rural Science, University of New England, Armidale, New South Wales 2350, Australia. \\ ${ }^{4}$ Departamento de Ingeniería Eléctrica, Electrónica, Automática y Física Aplicada, ETSIDI, Universidad Politécnica de \\ Madrid, 28040 Madrid, Spain. \\ * correspondence: david.garcia.callejas@gmail.com
}

\begin{abstract}
Theory posits that the persistence of species in ecological communities is shaped by their interactions within and across trophic levels. However, we lack empirical evaluations of how the structure, strength and sign of these interactions drive the potential to coexist in diverse multi-trophic communities. Here we model community feasibility domains, a theoretically-informed measure of coexistence probability, from empirical data on communities comprising more than 50 species for three trophic guilds (plants, pollinators, and herbivores). Although feasibility domains vary depending on the number of trophic guilds considered, we show that higher network connectance leads to lower coexistence opportunities. Moreover, empirical estimations of the feasibility domains were higher with respect to random network structures but lower than a mean-field approach, suggesting that observed interaction structures tend to maximize coexistence within its imposed limits. Our results stress the importance of incorporating empirically-informed interaction structures within and across guilds to better understand how species coexist in diverse multitrophic communities.
\end{abstract}

\section{Introduction}

Ecological communities are complex systems in which individuals of different species interact in a myriad of context-dependent ways, generating emergent properties that are not evident from the isolated study of their constituent elements (Levin, 1998). Understanding these emergent properties, such as community stability or resilience (Meerbeek et al., 2021) is key for strengthening the scientific basis of ecosystem conservation and restoration (Moreno-Mateos et al., 2020). This integrative perspective is well established conceptually, but has rarely been put to practice in the study of empirical communities. For example, empirical studies documenting different interaction types and quantifying their combined effects on community properties have only recently started to fill this gap from different angles (Evans et al. 2013; Kéfi et al., 2015, 2016, Melián et al., 2009. Morrison et al. | 2020, Sauve et al., 2014). These recent developments have been key for understanding the relationship of different interaction combinations in driving certain aspects of ecological stability, such as local asymptotic stability (Mougi \& Kondoh, 2012; Sauve et al. 2014), or for analyzing the structural importance of different species in a context of multiple interactions (Kéfi et al. 2016). Overall, there is increasing evidence that different interaction types contribute significantly and sinergistically to the emergent properties of ecological communities (Losapio et al. 2021). Yet, these recent insights come with a series of important theoretical and empirical limitations. From the theoretical side, challenges remain in integrating the influence of multiple interaction types on ecological stability García-Callejas et al. 2018) and coexistence (Godoy et al. , 2018). From the empirical side, there is a scarcity of empirical data on communities with different interactions, both within and across guilds, in which the strength of species interactions is quantified following a standardized way.

Early studies considering multiple interactions in empirical communities relied on binary networks that document the presence or absence of a given interaction, or interaction strengths inferred through indirect methods or expert opinion (see García-Callejas et al. (2018) for a review). While these type of networks are useful first approximations, documenting interactions quantitatively is essential for correctly interpreting community structure and dynamics (Banašek-Richter et al. 2009), as recently shown in an agricultural context (Morrison et al. 2020). However, even when using quantitative interactions, a remaining issue is the inherent difficulty of maintaining a common currency of effects across interaction types (Abrams, 1987). From an empirical perspective, it is particularly challenging to integrate the sampling of interactions between species of a trophic 
guild (i.e. intra-guild interactions, for example, competition among plant species) with other interactions across guilds (i.e. inter-guild interactions, for example, plant-pollinator mutualisms or plant-herbivore antagonisms). Interactions within and across guilds have been mostly integrated in the context of mutualisms between plants and pollinators by incorporating competitive interactions to these bipartite networks (Bastolla et al. 2009 Gracia-Lázaro et al., 2018, Wang et al. [2021), but the concept can be generalized to other interactions (Godoy et al. 2018: Seibold et al. 2018). However, even when these intra-guild interactions are considered, they are often modelled as a constant across all species (Bastolla et al. 2009 , Saavedra et al., 2013). This is because intra-guild interactions are notoriously difficult to quantify directly. This solution is suboptimal and lacks biological realism, as there is widespread evidence of differential intra-guild interaction strengths across species mediated by resource use, phenological differences, and many other processes. Such processes are likely to generate intra-guild interaction networks that, depending on the trophic guild considered, differ substantially in their structure and thus in their potential to maintain species diversity (Barabás et al. 2016). Empirical information on these processes can potentially be incorporated in the estimation of intra-guild interactions (Morales-Castilla et al. 2015).

In parallel to the limitations of provinding realistic quantifications of the full network of species interactions, methodological tools for the integration of this complexity in community-level frameworks are still under development (García-Callejas et al., 2018, Godoy et al. 2018, Pilosof et al., 2017). Classic modelling approaches to the study of community structure, dynamics, and stability in single-interaction networks can be adapted to deal with multiple interactions (García-Callejas et al. 2018). However, they often rely in an exponentially increasing number of parameters to be estimated as the number of species increases, which precludes their use for diverse empirical communities. Recent advances taking a structuralist approach provide an alternative to evaluate the role of species interactions in promoting or hindering multi-species coexistence (Godoy et al., 2018; Saavedra et al. 2017). This framework is built upon the idea that the structure of species interactions shapes the opportunities to coexist for the different species in a given community, by quantifying the so-called feasibility domain. The expectations arising from these concepts are clear: the larger the feasibility domain, the more likely the community can persist without any species going extinct. This is because communities with larger feasibility domains can withstand larger fluctuations in species vital rates without losing species. Thus, the structuralist approach emerges as a powerful bridge between theoretical studies on community stability and feasibility, and empirical quantifications of species interactions and the probability of multi-trophic systems to coexist.
Given these recent advances, the time is ripe to characterize and model how quantitative interaction structures within and across trophic guilds drive the opportunities of species and whole multi-trophic communities to coexist in the field. The outcomes of such exploration are not trivial to predict, as it involves factors whose relationship with multi-species coexistence have not yet been well established. For example, network complexity sensu lato is expected to decrease at least one facet of community stability, i.e. local asymptotic stability (May, 1972). Hence, we can hypothesize a similar negative relationship between complexity and the amplitude of the feasibility domain (Arnoldi \& Haegeman, 2016, Gibbs et al. 2018. Medeiros et al. 2021). In multi-trophic communities, this complexity is encoded in the number of species across different trophic guilds and their interactions with species of the same and other guilds. On the other hand, observed interaction structures have often been shown to overrule this negative complexity-stability relationship (Jacquet et al., 2016, Thébault \& Fontaine, 2010), but their effects on the feasibility domains of interaction networks composed by different types of interactions remain unclear (Grilli et al. 2017, Wang et al. 2021). From another angle, recent observational and experimental studies have focused on the persistence of single species in a multi-trophic context, showing that estimates of species persistence are radically altered when different interactions, within and across guilds, are explicitly considered both in mesocosms (Bartomeus et al. 2021) and in large-scale metawebs (Kéfi et al. . 2016). These scattered pieces of evidence open the door to ask if the opportunities for coexistence in complex natural communities, expressed through the feasibility domain, are driven by the structure of biotic interactions both within and across trophic guilds.

Here, we quantify multi-trophic ecological networks from nine Mediterranean grassland communities over two years involving a total of 108 taxa and their different types of interactions: plant-herbivore, plant-pollinator, and the intra and interspecific competitive interactions within guilds (plants, pollinators, and herbivores). With this comprehensive dataset, we investigate: 1) the opportunities to coexist of species in multi-trophic communities, expressed through their feasibility domain; 2) how the structure (both in intra-guild interactions and in the overall multi-trophic network) modulates this feasibility domain, by comparing the observed structures to two complementary null interaction structures; and 3 ) which network-level metrics, and to what extent, are related to the feasibility domain of multi-trophic communities. 


\section{Results}

We sampled a highly diverse Mediterranean annual grassland ecosystem during two years (2019 and 2020). Each year we gathered information on nine communities across an area of 2680 ha (Fig. 1. see Methods), documenting a total of 214 unique interactions among plants, 110 between plants and pollinators, and 160 between plants and herbivores. In this period we observed interactions between 108 taxa, of which 17 were plants, 46 herbivores, and 45 pollinators. Of these, 53 taxa representing $49 \%$ of the records were identified at the species level (17 plants, 16 pollinators, and 20 herbivores), and $51 \%$ as morphospecies (Table S1). The included taxa span diverse life-history strategies, such as grasses (e.g. Hordeum marinum) and forbs (e.g. Leontodon maroccanus) in the annual plant guild, solitary bees (e.g. from genera Andrena, Lasioglossum), flies (e.g. genera Sphaerophoria, Musca), or Lepidoptera (e.g. genera Lasiocampa, Thymelicus) within the pollinator guild, and sap feeders (e.g. Hemiptera from genera Aelia or Aphis), pollen feeders (e.g. Coleoptera from genera Malachius or Psilothrix) or leaf-eaters (e.g. Gastropoda from genera Theba or Cochlicella) within the herbivore guild (Table S1.

We constructed interaction matrices of the sampled communities using normalized observed interaction frequencies as a proxy for interaction effects between species, including plant-plant (Saiz et al., 2016), plant-pollinator (Vázquez et al. 2005), and plant-herbivore interactions (see Methods for details). In the case of intra-guild interactions between pollinators or herbivores, it is logistically unfeasible to obtain direct accounts of interactions among species of these guilds. Therefore, we obtained indirect estimates of resource competition by accounting for phenological overlap and quantity of shared resources (see Methods). We observed a high prevalence of forbidden interactions: $62.7 \%(640 / 1020)$ of plant-pollinator interactions and $49 \%(567 / 1156)$ of plant-herbivore interactions were morphologically unfeasible (due to incompatible morphological traits) or phenologically unfeasible (due to non-overlapping phenologies).

The frequency distribution of the 270 unique interactions observed across trophic guilds is highly skewed, with e.g. 128 interactions being observed less than five times. Plant richness is positively correlated with that of pollinators across communities, (Pearson's $\mathrm{r}=0.73$, $\mathrm{t}=4.3036, \mathrm{df}=16, \mathrm{p}$-value $<0.01)$ but not with herbivores (Pearson's $\mathrm{r}=-0.2, \mathrm{t}=-0.85851, \mathrm{df}=16, \mathrm{p}$-value $=0.4$ ). Richness values range from 30 taxa in the less diverse community to 52 in the most diverse, for an overall richness of 108 taxa across communities and years.

When plants, herbivores, and pollinators are considered independently, these guilds show structural differences in their competition networks. Plant competition networks are highly connected with low modularity, while herbivore ones are less connected, but more modular, and pollinator ones have intermediate values between these extremes (Fig. S1). The two bipartite networks (plant-pollinators and plant-herbivores) are structurally similar in terms of connectance, complexity, or their degree distribution, but plant-pollinator networks are more modular than plant-herbivore ones. This is likely due to the concentration of pollinator visits in a few plant species (mostly Leontodon maroccanus, Chamaemelum fuscatum, and Pulicaria paludosa). Notably, network structure was robust across space and time in our communities, showing more variability across guilds, or with the in silico experiments (see below), than across the observed communities. Connectance, for instance, varied significantly across guilds and types of community structure, but not across replicates (Type III Analysis of Variance, communities: $\mathrm{F}=178.7, \mathrm{df}=5$, p-value $<0.001$; structure type: $\mathrm{F}=168.3, \mathrm{df}=2, \mathrm{p}$-value $<$ 0.001 , replicate: $\mathrm{F}=1.54, \mathrm{df}=1, \mathrm{p}$-value $=0.21$ ).

We analyzed the opportunities to coexist in the observed communities when considering one, two, or three trophic guilds. The feasibility domain of a community quantifies its potential to coexist, and is directly obtained from the interaction matrix (see section "Community feasibility and structural patterns" in Methods). When analyzed independently from the rest of the community, plants display the lowest feasibility domains of the three guilds, with pollinators having the largest feasibility domains and herbivores intermediate values. In the communities with two guilds, plant-pollinator communities display consistently larger feasibility domains than plantherbivore ones. Finally, the community comprising the three trophic guilds shows intermediate values between the two-guild communities (Fig. 2). These results, thus, show a largely idiosyncratic relationship between the feasibility domain of our observed communities and the number of trophic guilds accounted for. Nevertheless, as a general trend, all communities and subsets of them display generally low feasibility domains (below 0.25 in virtually all cases, see Fig. 22, and the tendency appears to be towards lower feasibility domains in more complex communities.

In addition to the observed communities, we quantified the feasibility domains of two sets of in-silico modified communities. For the first set, we substituted the estimated intra-guild interactions for a mean-field approach in which all intra-guild interactions are set to a constant, mimicking current standard practices Bastolla et al. 2009, Rohr et al. 2014, Simmons et al. 2020); for the second set, we generated randomized versions of the observed interactions matrices, distributing interactions randomly while keeping the number of interactions fixed for every taxa (see Methods). These modified communities show a different picture with respect to the observed ones: first, the communities with an imposed mean-field intra-guild strength have the highest feasibility domain in all cases, and display a clearer tendency to lower the feasibility domain as the number of trophic guilds increases. Second, the randomized counterparts of the ob- 

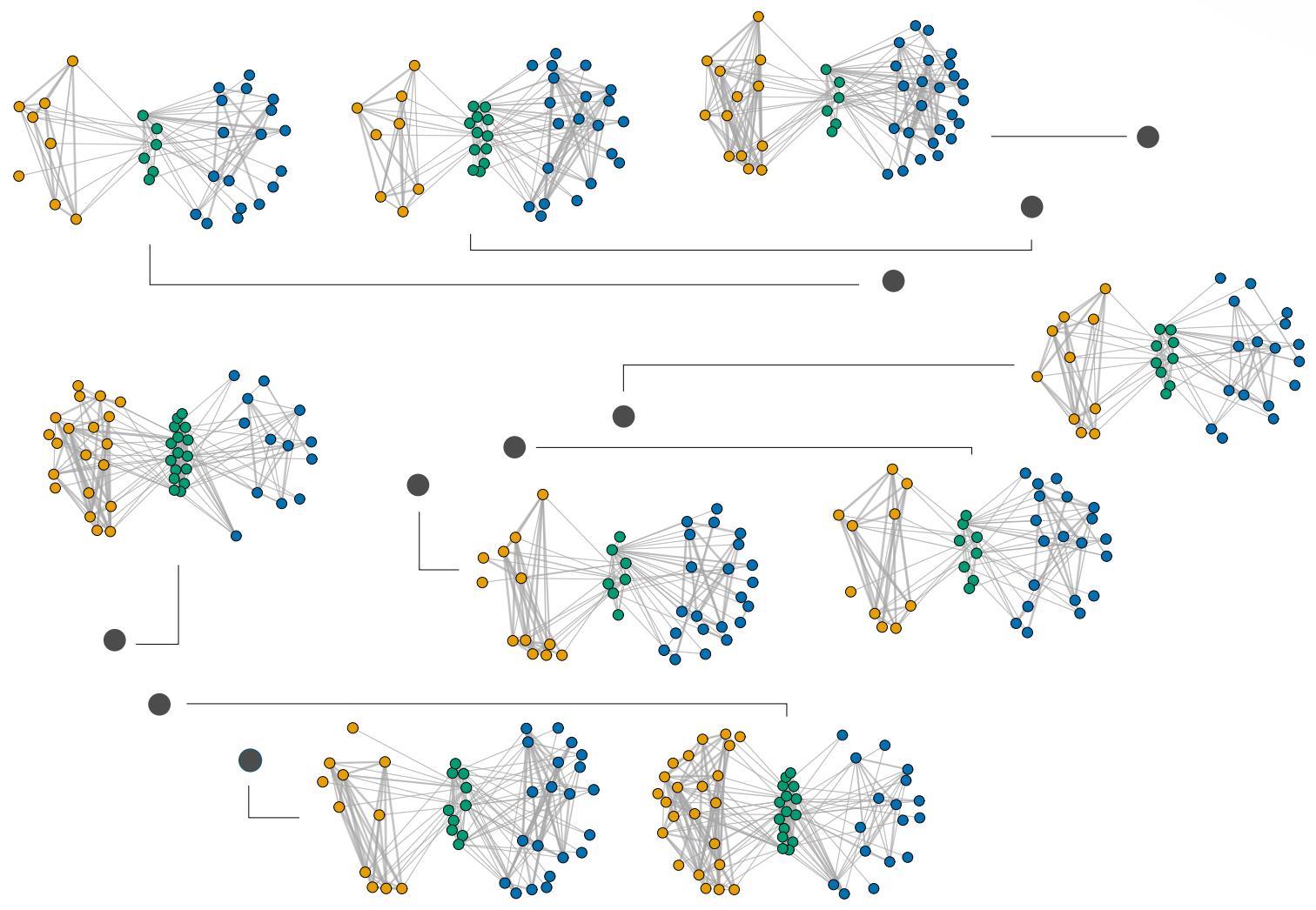

Fig. 1. Approximate spatial configuration of the sampled networks. For reference, we show the 9 networks of 2019, with pollinators in orange, plants in green, and herbivores in blue. Lines represent the presence of interactions observed in the field or estimated from field information.

served multi-trophic structures have very low average feasibility domain in most cases, except for pollinators and herbivores alone (Fig. 2), indicating very restricted opportunities for coexistence in random multi-trophic communities. Differences between guilds and between interaction structures are significant overall (Type III Analysis of Variance, communities: $\mathrm{F}=8.96, \mathrm{df}=5$, p-value $<0.001$; interaction structure: $\mathrm{F}=25.36, \mathrm{df}=$ 2 , p-value $<0.001)$, as well as their interaction $(\mathrm{F}=$ $4.57, \mathrm{df}=10, \mathrm{p}$-value $<0.001)$. Therefore, when comparing the observed communities with the two modified structures, we observed a consistent ranking in the values of the feasibility domains, from the comparatively highest values of communities with mean-field competition to the lowest values of fully randomized interaction structures. This suggests that realistic configurations of interaction distributions maximize opportunities to coexist, but only with regards to ecologically realistic constraints.

Lastly, we analyzed the relationship between the feasibility domain of the 18 observed multi-trophic communities (i.e. the communities including plants, herbivores, and pollinators) and their connectance and heterogeneity of their degree distribution (quantified as the Gini index of the degree distribution). We selected these representative metrics given their overall importance in ecological network analyses (Carpentier et al. 2021. Delmas et al. 2018) and their importance in capturing the variability observed in our data (see Supplementary Section "Network Metrics" and Fig. S2 2. These two metrics are not correlated in our dataset (Pearson's $\mathrm{r}=-0.09, \mathrm{t}=$ $-0.39, \mathrm{df}=16, \mathrm{p}$-value $=0.7)$. Furthermore, we chose not to include more network-level metrics as predictors given the logistic limitations to obtain more replicates of our multi-trophic communities, and favouring parsimony and interpretability of the statistical model. We ran a Generalized Linear Model that showed a negative and statistically significant relationship between feasibility domain and both metrics (Table 1 . Fig. 3 and Fig. S3.

\begin{tabular}{lrrrr}
\hline Predictor & estimate & $\mathrm{SE}$ & $\mathrm{t}$ & $\mathrm{p}$-value \\
\hline Intercept & -3.0007 & 0.1254 & -23.923 & $<0.001$ \\
connectance & -0.6687 & 0.1297 & -5.157 & $<0.001$ \\
degree distribution & -0.6497 & 0.1297 & -5.010 & $<0.001$ \\
\hline
\end{tabular}

Table 1. Estimated regression parameters, standard errors, $t$-values and $\mathrm{p}$ values for the Generalized Linear Model relating feasibility domain with connectance and degree distribution (gamma distribution with log link function, N $=18)$.

\section{Discussion}

Our results provide empirical evidence that the opportunities to coexist in complex communities depend crucially on the structure of both intra- and inter-guild interaction networks. In particular, empirically observed 
bioRxiv preprint doi: https://doi.org/10.1101/2021.11.29.470335; this version posted November 30, 2021. The copyright holder for this preprint (which was not certified by peer review) is the author/funder, who has granted bioRxiv a license to display the preprint in perpetuity. It is made available under aCC-BY-NC 4.0 International license.

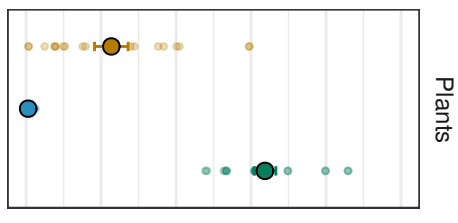

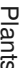
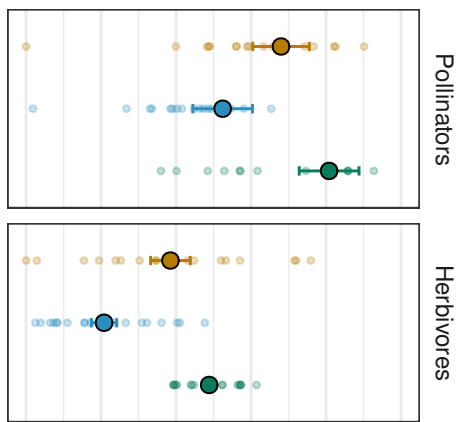

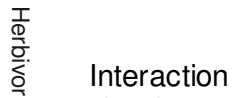 \\ structure}

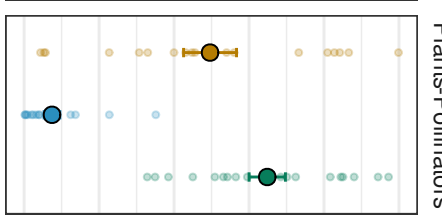

-O- Observed

- - Randomized

- Mean field
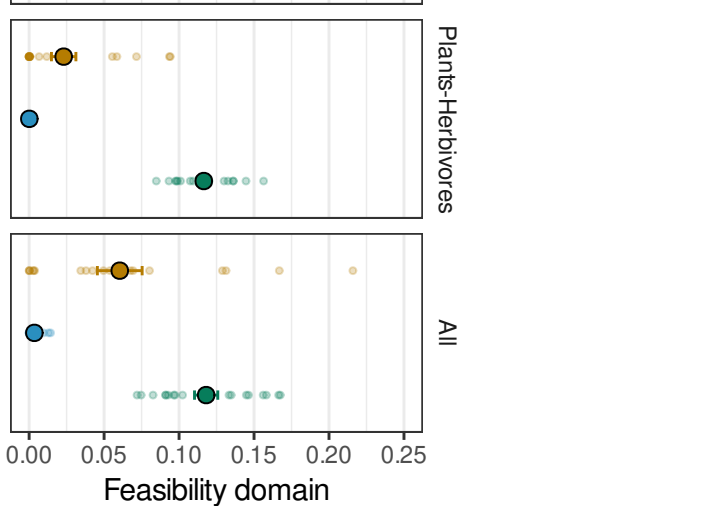

Fig. 2. Feasibility domain for each community and interaction structure type (for reference, feasibility domains range in the interval [0,0.5]). Error bars represent the standard error of the average feasibility domain, where this average is obtained from the 18 replicates of each community. Smaller points represent the 18 replicates. For visibility, we removed two outliers in the second panel (pollinators) from each type, with values between 0.3 and 0.5

A)

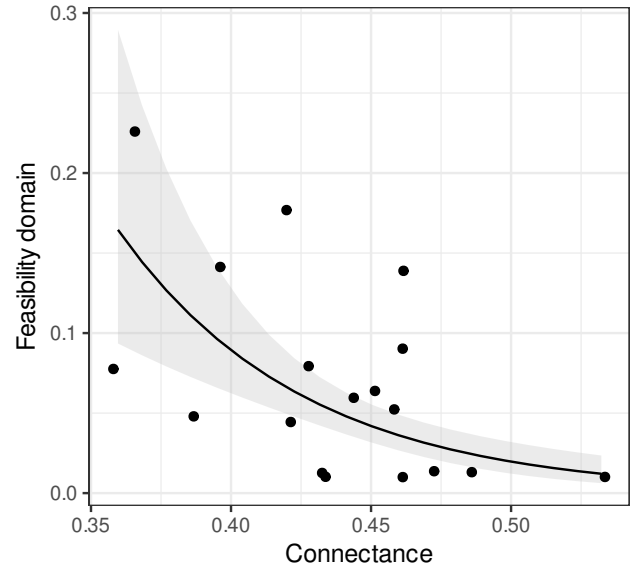

B)

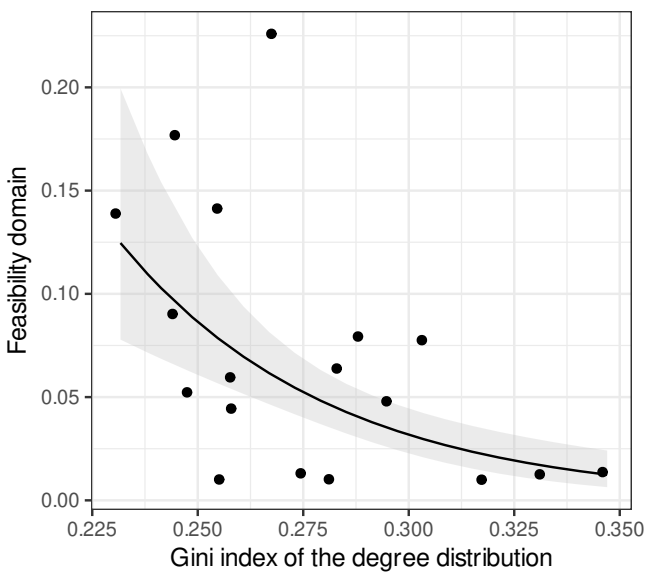

Fig. 3. Feasibility domain of the observed communities $(\mathrm{N}=18)$, and its relationship with connectance (panel $A)$, and the heterogeneity of the degree distribution measured as its Gini index (with increasing Gini index expressing higher heterogeneity, panel B). Fitted lines correspond to the Generalized Linear Model summarized in Table 1 Shaded regions represent $95 \%$ confidence intervals. Note that here we plot both predictors and the fitted model in observed values for clarity, but the GLM was performed with scaled values. 
interaction structures consistently display higher opportunities to coexist than randomized ones, suggesting that multi-species coexistence and the overall interaction structure of natural communities are tightly related. Furthermore, we show that the assumption of mean-field competitive interactions artificially increases in our system the opportunities to coexist in our multitrophic communities. These results rest upon observations from highly diverse communities comprising three distinct trophic guilds: annual plants, their pollinators, and their insect and gastropod herbivores. Evaluating the opportunities to coexist of different subsets of these communities we observe mostly idiosyncratic responses, with a trend towards lower feasibility domains in communities with more trophic guilds. Hence, our results emphasize that the community context, both in terms of trophic guilds and interaction structure, is key for estimating multi-species coexistence ( $\mathrm{Pauw}, 2013)$.

The hypothesis that realistic interaction structures maximize different facets of community stability with respect to random interactions has been repeatedly brought up to explain the apparent persistence of empirical communities (Jacquet et al., 2016). We show that correctly recovering empirical interaction structures is, in particular, key for evaluating multi-species coexistence. Indeed, the randomized communities in our study, especially considering two or three guilds, display almost null feasibility domains. This result provides a novel angle to the complexity-stability debate, showing that multi-trophic random communities are virtually unfeasible, even with ecologically sound constraints to the randomization (Dougoud et al. 2018). As our randomization scheme can potentially assign non-zero coefficients to forbidden interactions, this result also highlights the importance of correctly accounting for these forbidden interactions in structural analyses of ecological networks (Olesen et al. , 2011). This result contrasts with a previous study by Grilli and coleagues (Grilli et al. , 2017) that showed that structural patterns of empirical networks were either less feasible than random networks (for food webs) or similarly feasible (for mutualistic networks). These differences may lie in the explicit consideration in our study of (i) different interaction types, and (ii) forbidden interactions. In any case, further studies across ecosystems and interaction types are needed to confirm the results presented here.

The results from our study are built from observed interaction structures both within and among trophic guilds. As difficult as different interactions among guilds are to document in the field in a comprehensive manner (Jordano, 2016), interactions within a single trophic guild can be even harder to quantify, as they often rely on indirect, resource-mediated forms of competition or facilitation, e.g. acquisition of nectar and pollen Ashman et al. 2020). Mean-field approximations assume that competition exists between species of the same trophic guild, but is completely homogeneous. While such a general assumption about intra-guild interactions is warranted for communities with limited information on them, a more detailed accounting is shown, here and in other recent studies (Bartomeus et al., 2021, GraciaLázaro et al. 2018, Wang et al. |2021), to significantly alter the conclusions regarding its influence on community dynamics. In particular, the artificial increase in feasibility domain as we simplify our intra-guild communities to a mean-field setting is expected for communities with relatively low diversity. This is because the mean-field approach ensures that intraspecific interactions outweigh interspecific ones, granting multispecies coexistence in this particular case of fully connected, symmetric interaction matrices (Barabás et al., 2016).

While general quantitative relationships between multitrophic interaction structures and multi-species coexistence remain far from settled, we report a clear correlational trend between network-level metrics of ecological communities and their feasibility domain (Fig. 3): the opportunities to coexist in the multi-trophic communities studied here decrease significantly with increasing connectance, and with increasing degree heterogeneity. Although these relationships have not been explored theoretically, they mirror recent results documenting negative connectance-robustness relationships in multitrophic networks across agricultiral intensification gradients (Morrison et al. 2020). Thus, multi-trophic coexistence may be increasingly fragile as the number of interactions in a community or their heterogeneity increase because narrow feasibility domains can hardly accommodate variability in species vital rates or, indirectly, in environmental perturbations to these vital rates (Song et al. 2018b). Indeed, as feasibility domains narrow, an increasing degree of functional equivalence in terms of vital rates is required to grant multi-species coexistence. That is, if species show large differences in vital rates, leading to high fitness differences sensu (Saavedra et al. 2017), they are likely to exclude each other. Recent evidence from theoretical studies (Sakavara et al. 2018. Scheffer et al. 2018) backed up by empirical observations (García-Callejas et al., 2021, Wiegand et al. 2021) suggests that this may indeed be the case, and coexistence in diverse communities can be achieved through increasing functional equivalence rather than through strong niche differentiation among species. If this emergent neutrality hypothesis (Scheffer et al. 2018) holds more generally, and across trophic guilds, it may be reflected in the tension between the feasibility domain of diverse communities and the functional equivalence, in terms of vital rates, of their constituent species.

On a broader scope, an important limitation of these arguments that also applies to our study is that stability -in its different dimensions- is usually quantified assuming closed systems, and in particular, here we consider independence among communities, given their spatial separation, and from one year to the next (see Methods). This is justified in seasonal systems with strong 
soil heterogeneity and which are reset each phenological year (García-Callejas et al. 2021), but might not be appropriate for communities without spatial and temporal independence. The inclusion of spatial processes on the study of ecological stability has shown the importance of organismal movement across patches in granting stability, through mechanisms such as source-sink dynamics (Gravel et al. 2016) or spatial insurance (Thompson et al., 2017). In our study system, despite the spatial distance between our communities makes spatial independence a sensible first assumption, highly mobile species such as flying pollinators can easily link the different plots. Therefore, it is not suprising that we found only marginally feasible or inherently unfeasible communities on their own. In this view, long-term empirical coexistence can only be maintained through source-sink processes in which transient species would collapse in the absence of these spatial dynamics (Huffaker, 1958). In our system, in particular, we observed in a previous study a small but sizeable set of transient plant species (García-Callejas et al. 2021). More generally, however, the prevalence of transient species in complex multi-trophic communities and their influence in different facets of community stability remain open questions.

To explore in greater detail the multi-species coexistence in empirical communities, estimates of intrinsic growth rates for every taxa included are needed. Such finescale estimation is challenging even for highly simplified communities (Bartomeus et al., 2021), and thus is logistically unfeasible for field observations of more diverse communities. Given these limitations, and the equally stringent data requirements of more mechanistic population dynamics models (e.g. Gauzens et al. (2020)), we reinforce here the idea that the feasibility domain can be a useful probabilistic approximation to multi-species coexistence and stability (Saavedra et al. 2020$)$. This metric can be obtained from interaction frequencies if these are assumed to be a good proxy of overall species effects, which is generally the case for insect pollinators (Vázquez et al. 2012), and in the case of intraguild interactions, from proxies of competition based on resource overlap (Morales-Castilla et al., 2015). Using interaction frequencies as a proxy for overall interaction strengths is nevertheless a first approximation in the absence of better resolved data (Novella-Fernandez et al. 2019). For example, further refinements of this methodology can account for varying per-capita efficiencies in pollen transportation for pollinators, or in plant damage for herbivores, which will further unveil the relative importance of species traits in shaping the coexistence potential of ecological communities.

Overall, our study provides evidence that analyzing multi-species coexistence requires an integrative view of ecological communities: isolated studies of subsets of the trophic guilds present in any community can be underor over-estimating the opportunities of species to coexist. Equally important, the structure of different inter- action types both within and across guilds can strongly influence coexistence outcomes. Primary network metrics are, furthermore, empirically related to the feasibility domain of our studied communities, opening the door to relate structural and dynamical network propierties. Although quantifying ecologically relevant guilds and interactions in different types of natural communities can be extremely challenging, only by advancing in the biological realism of community characterizations we will be able to move towards better understanding the determinants of ecological coexistence. 


\section{Methods}

\section{Data collection}

We conducted our study in a Mediterranean grassland community located in Doñana National Park (SW Spain, $37^{\mathrm{o}} 04^{\prime} 01.5$ "N, $\left.6^{\mathrm{o}} 19^{\prime} 16.2^{\prime \prime} \mathrm{W}\right)$. We set up 9 plots of 8.5 $\mathrm{m}^{2}$ from which we documented 1) the spatial associations between plant individuals, which we used as proxies for competitive interactions among plants, 2) direct interactions between plants and pollinators, and 3) direct interactions between plants and herbivores. We expect these guilds to be the most relevant for the dynamics of the community, as the abundance of predators (e.g. spiders) is relatively low, and there are no consistent effects of other animals of higher size. For plant-plant interactions, we obtained the number of local co-occurrences between plant individuals, sampling 36 focal individuals of each plant species per plot and their plant neighbours at a radius of $7.5 \mathrm{~cm}$. This radius is a standard distance used in previous studies to measure competitive interactions among annual plant species (Levine \& HilleRisLambers, 2009, Mayfield \& Stouffer, 2017), and has been validated to capture the outcome of competition interactions at larger scales $\left(1 \mathrm{~m}^{2}\right)$ under locally homogeneous environmental conditions (Godoy \& Levine, 2014). Interactions between plants and pollinators or herbivores were sampled from the emergence of the earliest flowers (February) to the decay of the latest ones (June). Specifically, we recorded the number of floral visits to each plant species, by sampling each plot for $30 \mathrm{~min}$ on a weekly basis for a total of 148.5 hours in 2019 and, on a bi-weekly basis for a total of 54 hours in 2020. We only recorded floral visitors that contacted plant's reproductive organs (pistil and/or anthers), and hence we assume they are effective pollinators and refer to them that way throughout the text. Lastly, plant-herbivore interactions were sampled in a similar manner: we surveyed each plot for $36 \mathrm{~min}$, and associated herbivore species with plant ones when we observed a herbivore on the stem, leaves, or flowers of the plant.

Plots were sampled weekly from February to June in 2019 and 2020, except for five weeks in March/April 2020 due to covid-19 restrictions. From these data, we obtained 18 normalized block interaction matrices $\mathbf{A}_{p, t}$ (9 plots $\times 2$ years) considering both intra-guild competition and inter-guild interactions, such that for a given plot $n$ and year $t$ :

$$
\left.\mathbf{A}_{\mathbf{n}, \mathbf{t}}=\begin{array}{ccc}
P & L & H \\
& H \\
\boldsymbol{\alpha}_{n, t}^{(p, l)} & \boldsymbol{\alpha}_{n, t}^{(l)} & 0 \\
\boldsymbol{\alpha}_{n, h)}^{(p, t)} & 0 & \boldsymbol{\alpha}_{n, t}^{(h, p)}
\end{array}\right]
$$

where $P=$ plants, $L=$ pollinators, and $H=$ herbivores. The $\boldsymbol{\alpha}$ elements represent the different submatrices (or blocks) of the community, e.g. $\boldsymbol{\alpha}^{(p)}$ represents the matrix of plant-plant interactions, $\boldsymbol{\alpha}^{(l, p)}$ the matrix of pollinator effects over plants, and so on.

\section{Intra-guild interactions}

Estimating the occurrence and strength of interactions among the members of a guild is a pervasive problem in studies of ecological networks, in particular when individuals are highly mobile and/or difficult to track in the field. This is the case, for example, for arthropod pollinators and herbivores. A first approach to account for these intra-guild interactions in bipartite networks has been to assume that intra-guild competition occurs, and affects all species equally and in a symmetric way. Theoretical studies taking this approach highlighted that, under mean-field competition, the role of nested network architectures is key for maximizing species persistence in mutualistic networks (Bastolla et al. 2009). These ideas have been refined recently, again considering mutualistic networks, and as expected, accounting for structured intra-guild competition fundamentally alters the expectations in terms of species persistence, by generating mutualism-competition trade-offs Gracia-Lázaro et al. 2018, Wang et al. 2021). These recent advances, however, structure intra-guild competition by relying solely on overlap of resource use, without considering, for example, phenological constraints that are commonly observed in natural communities (Olesen et al., 2011). A robust quantification of intra-guild interaction patterns could therefore be advanced by considering a hierarchical categorization of interactions that considers different filters for interaction occurrence and intensity, based on ecological first-principles (Morales-Castilla et al., 2015). For example, assuming that there are not preempting processes (i.e. the amount of soil water, light or food is not altered by earlier taxa), then species within the same guild will not compete for common resources if they do not overlap phenologically. This assumption is a parsimonious starting point in the absence of better information, particularly given the wide variability observed regarding nectar production dynamics in the field (Pacini \& Nepi, 2007) and the lack of specific studies with our plant populations.

For building our intra-guild interaction matrices, we standardized the two different sampling designs used to collect plant-plant interactions and plant-animal interactions (see section Data Collection) through a common methodology. For plants, the direct observations of plant-plant spatial associations are the starting point of the standardization. These are represented in a plantplant square matrix per community, that we name $\mathbf{P}_{n, t}$ for the community in plot $n$ and year $t$. For pollinators and herbivores, we converted plant-animal observations to pollinator-pollinator and herbivore-herbivore square matrices by calculating the resource overlap between two species $i$ and $j$ as the relative number of interactions from $i$ with hosts shared with $j$, thus building two square matrices $\mathbf{L}_{n, t}$ and $\mathbf{H}_{n, t}$.

Once the plant, pollinator, and herbivore matrices are in the same square form, the next steps are common to all of them. First, the elements of these matrices are 
weighted by the phenological overlap between each pair of species. The phenological overlap between species $i$ and species $j$ in a given year is the activity period in which both species are observed relative to the full activity period of species $i$. We define the activity period of species $i$ in a given year as the interval between species $i$ 's first and last observations recorded in the entire field that year. Note that this implies that the phenological overlap between any two species can potentially be asymmetric. We thus obtained one phenological overlap matrix $\mathbf{O}_{t}^{(g)}$ for each trophic guild $g$ and year $t$.

The result of multiplying element-wise the initial square matrices $\mathbf{P}_{n, t}, \mathbf{H}_{n, t}, \mathbf{L}_{n, t}$ by the phenological overlap matrices $\mathbf{O}_{t}^{(p)}, \mathbf{O}_{t}^{(l)}, \mathbf{O}_{t}^{(h)}$ is a set of square matrices weighted by phenology, named $\mathbf{O} \mathbf{P}_{n, t}, \mathbf{O} \mathbf{H}_{n, t}, \mathbf{O L} \mathbf{L}_{n, t}$. In order to standardize these matrices, in a last step we divide each element by the sum of all elements in the matrix, i.e. for plants:

$$
\boldsymbol{\alpha}_{n, t}^{(p)}=\frac{\mathbf{O P}_{n, t}}{\sum_{i, j}\left(\mathbf{O P}_{n, t}\right)_{i j}}
$$

This normalization implies that the elements of the resulting $\boldsymbol{\alpha}$ matrices sum to 1 . In ecological terms, this assumes that every matrix has an identical weight in the full community $\mathbf{A}_{n, t}$, or in other words, that every interaction has an identical net effect on the community. Also note that, up to this point, all matrices are non-negative. Thus, negative signs are imposed to the resulting $\boldsymbol{\alpha}$ matrices when appropriate: all inter-guild competition matrices, and herbivore effects on plants.

\section{Inter-guild interactions}

Given the observational data with the number of visits from a certain species of pollinator (or herbivore) $i$ to a certain plant species $j$, we obtained the normalized interaction intensity by dividing each element of the original bipartite matrix by the sum of all matrix elements (eq. 22. As with the intra-guild matrices, this ensures inter-guild coefficients in the range $[0,1]$ and that the sum of all elements in each matrix equals 1 . Likewise, the sign structure (e.g. $(+,+)$ relationships for plantspollinators, $(-,+)$ for plants-herbivores) is imposed directly over the resulting matrices. Overall, aside from the assumption of equal interaction effect on the full community, this assumes that the population-level interaction effect between a plant species and a pollinator or herbivore is given by the number of visits observed in the field (Vázquez et al. 2005). This assumption is a sensible approximation given that all inter-guild interactions recorded are plant-insect interactions whereby all insects have body sizes $<5 \mathrm{~cm}$, and that pollinator and herbivore interactions vary only in one order of magnitude (e.g. maximum number of interactions observed for herbivores is 7074 for Cochlicella barbara and for pollinators is 500 (Dilophus spp). Thus, the elements of the inter-guild matrices (e.g. $\boldsymbol{\alpha}_{n, t}^{p, h}$ for effects of herbivores over plants in plot $n$ and year $t$ ) represent populationlevel effects between any two taxa, a formulation that has already been used in the structuralist framework (Song et al., 2018a).

\section{Forbidden interactions}

Network metrics are affected by the existence, or lack thereof, of species interactions that cannot be realized. For example, in estimating the connectance of a given network with $S$ species, the set of potential links in it is taken to be $S^{2}$, i.e. the whole set of potential combinations of species pairs. If some species pairs do not interact, and cannot possibly interact, this set of potential links is overestimated. These interactions that cannot occur are named "forbidden interactions" or "structural zeros" (Olesen et al. 2011). We explicitly accounted for these forbidden interactions in quantifying networklevel metrics (Table S1). We estimated forbidden interactions in our communities, first in the intra-guild overlap matrices by considering phenological overlap, as discussed above, and second for the inter-guild interactions (plant-pollinators and plant-herbivores). For the interguild interactions we took a similar approach as with the intra-guild ones, filtering by phenological overlap and, in this case, also by morphological traits. In particular, we set to zero the potential interactions between grasses (Poaceae: Hordeum marinum, Parapholis incurva, Polypogon maritimus, Polypogon monspeliensis) and pollinators, and also between grasses and florivore herbivores. We also assumed that neither Lepidoptera nor Hymenoptera are able to pollinate the Quenopodiaceae present in our system (Beta macrocarpa and Salsola soda), due to their extremely small flowers. Melilotus species are Fabaceae whose flowers are morphologically adapted to pollination by comparatively robust insects, so we set to zero the potential interactions with Diptera. Regarding phenology, we set to zero the interactions between flowering plants and pollinators or florivores, if these did not overlap in any of the field seasons.

\section{Mean-field and null matrices}

For each plot and year, we thus compiled both intraand inter-guild interaction matrices for plants, herbivores, and pollinators, resulting in 6 interaction matrices per plot and year: three intra-guild communities $\boldsymbol{\alpha}^{p}, \boldsymbol{\alpha}^{l}, \boldsymbol{\alpha}^{h}$; two two-guild communities (one formed by plants and herbivores $\left(\boldsymbol{\alpha}^{p}, \boldsymbol{\alpha}^{h}, \boldsymbol{\alpha}^{p, h}, \boldsymbol{\alpha}^{h, p}\right)$, and one formed by plants and pollinators $\left.\left(\boldsymbol{\alpha}^{p}, \boldsymbol{\alpha}^{l}, \boldsymbol{\alpha}^{p, l}, \boldsymbol{\alpha}^{l, p}\right)\right)$; and the overall community represented by the full blockmatrix A (eq. 1). In addition to the observed matrices, we built two sets of in-silico complementary matrices designed to test the effects on the multi-trophic feasibility domain of 1) mean-field or structured intra-guild competition, and 2) the overall role of multi-trophic structure. For testing the importance of structured intraguild competition, we replicated the observed communities replacing the estimated intra-guild matrices $\boldsymbol{\alpha}^{p}, \boldsymbol{\alpha}^{l}$, and $\boldsymbol{\alpha}^{h}$ with mean-field matrices $\overline{\boldsymbol{\alpha}}^{p}, \overline{\boldsymbol{\alpha}}^{l}$, and $\overline{\boldsymbol{\alpha}}^{h}$, generated following Bastolla et al. (2009). In particular, we set a constant value to all species pairs, includ- 
ing intraspecific coefficients. We set these values to $\boldsymbol{\alpha}_{i, j}=-0.2$ and $\boldsymbol{\alpha}_{i, i}=-1$ (Saavedra et al., 2013 ).

Secondly, we analyzed the importance of multi-trophic network structure by constructing randomized versions of our observed matrices, in which we reshuffled the number of plant-plant interactions for each pair, as well as the number of plant-pollinators and plantherbivore interactions, while keeping the row and column totals fixed. From these rewired matrices, denoted $\stackrel{\circ}{\boldsymbol{\alpha}}^{p}, \stackrel{\circ}{\boldsymbol{\alpha}}^{p, l}, \stackrel{\circ}{\boldsymbol{\alpha}}^{p, h}, \stackrel{\circ}{\mathbf{A}}$, we also obtained the associated intra-guild matrices $\stackrel{\circ}{\boldsymbol{\alpha}}$, and $\stackrel{\circ}{\boldsymbol{\alpha}}$. We implemented these randomized, or null, communities using the algorithm r2dtable in the bipartite $\mathrm{R}$ package v2.16 (Dormann et al. 2009). In these null communities we also did not consider the forbidden interactions empirically obtained for the plant-herbivore and plant-pollinator interactions, such that a number of interactions $>0$ can potentially be assigned to an interaction marked as forbidden. Overall, for each of the 18 communities ( 2 years $\times 9$ plots), we analyzed the field-derived community represented by the matrix $\mathbf{A}$, the community with mean-field intra-guild matrices $\overline{\mathbf{A}}$, and the average values from 100 replicates of null communities $\stackrel{\circ}{\mathbf{A}}$.

\section{Community feasibility and structural patterns}

The potential for a given structure to sustain feasible communities is quantified via its feasibility domain, which when normalized ranges in the interval $[0,0.5]$ (Song et al. 2018b). A large feasibility domain indicates a higher potential to accommodate variations in species growth rates while maintaining feasibility, and viceversa. In mathematical terms, given an interaction matrix A for $s$ species, its feasibility domain is defined as

$$
D_{F}(\mathbf{A})=\left\{\mathbf{r}=N_{1}^{*} \boldsymbol{\nu}_{\mathbf{1}}+\ldots+N_{s}^{*} \boldsymbol{\nu}_{\boldsymbol{s}}, \text { with } N_{1}^{*}>0, \ldots, N_{s}^{*}>0\right\}
$$

where the vector $\boldsymbol{\nu}_{\boldsymbol{j}}$ is the negative of the $j$ th columns of the interaction matrix A, the vector $\mathbf{r}$ represents species' intrinsic growth rates in a classic Lotka-Volterra system, and $\mathbf{N}^{*}=-\mathbf{A}^{-1} \mathbf{r}$ is the vector of abundances when the feseable equilibrium exists (Song et al., 2018b). This quantity is then normalized with respect to the full parameter space (see eq. 5 in Song et al. (2018b) for more details), and throughout the study we refer to normalized feasibility domains, omitting "normalized" for brevity. We calculated the feasibility domain of each of the community networks constructed, i.e. for each community $\mathbf{A}_{n, t}$ we calculated the feasibility domain of each of the sub-communities of one guild and two guilds, as well as for the full multi-trophic community. Furthermore, for each network we also obtained a series of structural metrics that have been shown to be related to community stability in single-interaction networks, namely connectance, complexity, heterogeneity of the degree distribution, ratio between intra and interspecific interaction strength, heterogeneity of the inter- action strength distribution, and modularity (see Table S2 for definitions and details of the implementation). Forbidden interactions were explicitly accounted for obtaining connectance and modularity values; see associated $\mathrm{R}$ code (Section Data and code availability).

We analyzed the relationship between the feasibility domain and key network metrics of the 18 observed communities comprising the three trophic guilds, i.e. we discarded for this analysis the mean-field and null transformations, and the sub-communities of one or two guilds, for consistency. For this, we first explored with a Principal Component Analysis how our multi-trophic communities are distributed according to the different metrics. Then, from this analysis we selected representative community metrics and evaluated the relationship between the feasibility domain of the multi-trophic communities with the selected metrics through a generalized linear model with a gamma distribution on the scaled variables, to restrict the outcome to positive real values, and a log link function. We checked model diagnostics with the R package DHARMa v0.4.1 (Hartig, 2021). Given the limited number of replicate communities (9 plots sampled in 2 years), it is not advised to consider more complex model structures, such as accounting for variation across plots or years explicitly through random effects (Harrison et al. 2018). Conceptually, all 9 plots are sufficiently separated in space (average distance between plots is $>100 \mathrm{~m}$ ) to be reasonably considered as spatially independent, and the seasonal nature of the system supports the temporal independence of the communities, in the absence of more observations. We nevertheless tested a generalized linear mixed model with plot as random effect, that rendered similar negative and significant trends as the reported GLM, but whose residual diagnostics showed problems with the random effect addition.

\section{Bibliography}

Abrams, P. A. (1987). On classifying interactions between populations. Oecologia, 73, 272-281.

Arnoldi, J.-F. \& Haegeman, B. (2016). Unifying dynamical and structural stability of equilibria. Proceedings of the Royal Society A: Mathematical, Physical and Engineering Sciences, 472, 20150874.

Ashman, T.-L., Alonso, C., Parra-Tabla, V. \& ArceoGómez, G. (2020). Pollen on stigmas as proxies of pollinator competition and facilitation: Complexities, caveats and future directions. Annals of Botany, 125, 1003-1012.

Banašek-Richter, C., Bersier, L. F., Cattin, M. F., Baltensperger, R., Gabriel, J. P., Merz, Y., Ulanowicz, R. E., Tavares, A. F., Williams, D. D., De Ruiter, P. C., Winemiller, K. O. \& Naisbit, R. E. (2009). Complexity in quantitative food webs. Ecology, 90, 1470-1477.

Barabás, G., J. Michalska-Smith, M. \& Allesina, S. (2016). The effect of intra- and interspecific competi- 
tion on coexistence in multispecies communities. The American Naturalist, 188, 333-341.

Bartomeus, I., Saavedra, S., Rohr, R. P. \& Godoy, O. (2021). Experimental evidence of the importance of multitrophic structure for species persistence. Proceedings of the National Academy of Sciences, 118, e2023872118.

Bastolla, U., Fortuna, M. A., Pascual-García, A., Ferrera, A., Luque, B. \& Bascompte, J. (2009). The architecture of mutualistic networks minimizes competition and increases biodiversity. Nature, 458, 1018-20.

Carpentier, C., Barabás, G., Spaak, J. W. \& De Laender, F. (2021). Reinterpreting the relationship between number of species and number of links connects community structure and stability. Nature Ecology 8 Evolution, 5, 1102-1109.

Delmas, E., Besson, M., Brice, M.-H., Burkle, L. A., Riva, G. V. D., Fortin, M.-J., Gravel, D., Guimarães, P. R., Hembry, D. H., Newman, E. A., Olesen, J. M., Pires, M. M., Yeakel, J. D. \& Poisot, T. (2018). Analysing ecological networks of species interactions. Biological Reviews, 94, 16-36.

Dormann, C. F., Frueund, J., Bluethgen, N. \& Gruber, B. (2009). Indices, graphs and null models: analyzing bipartite ecological networks. The Open Ecology Journal, 2, 7-24.

Dougoud, M., Vinckenbosch, L., Rohr, R. P., Bersier, L.F. \& Mazza, C. (2018). The feasibility of equilibria in large ecosystems: A primary but neglected concept in the complexity-stability debate. PLOS Computational Biology, 14, e1005988.

Evans, D. M., Pocock, M. J. O. \& Memmott, J. (2013). The robustness of a network of ecological networks to habitat loss. Ecology letters, 16, 844-852.

García-Callejas, D., Bartomeus, I. \& Godoy, O. (2021). The spatial configuration of biotic interactions shapes coexistence-area relationships in an annual plant community. Nature Communications, 12, 6192.

García-Callejas, D., Molowny-Horas, R. \& Araújo, M. B. (2018). Multiple interactions networks: Towards more realistic descriptions of the web of life. Oikos, 127, 522.

Gauzens, B., Rall, B. C., Mendonça, V., Vinagre, C. \& Brose, U. (2020). Biodiversity of intertidal food webs in response to warming across latitudes. Nature Climate Change, 10, 264-269.

Gibbs, T., Grilli, J., Rogers, T. \& Allesina, S. (2018). Effect of population abundances on the stability of large random ecosystems. Physical Review E, 98, 022410.

Godoy, O., Bartomeus, I., Rohr, R. P. \& Saavedra, S. (2018). Towards the integration of niche and network theories. Trends in Ecology \& Evolution, 33, 287-300.

Godoy, O. \& Levine, J. M. (2014). Phenology effects on invasion success: Insights from coupling field experiments to coexistence theory. Ecology, 95, 726-736.

Gracia-Lázaro, C., Hernández, L., Borge-Holthoefer, J. \& Moreno, Y. (2018). The joint influence of competi- tion and mutualism on the biodiversity of mutualistic ecosystems. Scientific Reports, 8, 9253.

Gravel, D., Massol, F. \& Leibold, M. A. (2016). Stability and complexity in model meta-ecosystems. Nature communications, 7, 12457.

Grilli, J., Adorisio, M., Suweis, S., Barabás, G., Banavar, J. R., Allesina, S. \& Maritan, A. (2017). Feasibility and coexistence of large ecological communities. $\mathrm{Na}$ ture Communications, 8, 14389-14389.

Harrison, X. A., Donaldson, L., Correa-Cano, M. E., Evans, J., Fisher, D. N., Goodwin, C. E. D., Robinson, B. S., Hodgson, D. J. \& Inger, R. (2018). A brief introduction to mixed effects modelling and multi-model inference in ecology. PeerJ, 6, e4794.

Hartig, F. (2021). DHARMa: Residual Diagnostics for Hierarchical (Multi-Level / Mixed) Regression Models. URL http://florianhartig.github.io/ DHARMa/ R package version 0.4.3.

Huffaker, C. (1958). Experimental studies on predation: dispersion factors and predator-prey oscillations. Hilgardia, 27, 343-383.

Jacquet, C., Moritz, C., Morissette, L., Legagneux, P., Archambault, P. \& Gravel, D. (2016). No complexity-stability relationship in empirical ecosystems. $\mathrm{Na}$ ture communications, 7, 12573.

Jordano, P. (2016). Sampling networks of ecological interactions. Functional Ecology, 30, 1883-1893.

Kéfi, S., Berlow, E. L., Wieters, E. A., Joppa, L. N., Wood, S. A., Brose, U. \& Navarrete, S. A. (2015). Network structure beyond food webs: Mapping nontrophic and trophic interactions on Chilean rocky shores. Ecology, 96, 291-303.

Kéfi, S., Miele, V., Wieters, E. A., Navarrete, S. A. \& Berlow, E. L. (2016). How structured is the entangled bank? the surprisingly simple organization of multiplex ecological networks leads to increased persistence and resilience. PLoS Biology, 14, 1-21.

Levin, S. A. (1998). Ecosystems and the Biosphere as Complex Adaptive Systems. Ecosystems, 1, 431-436.

Levine, J. M. \& HilleRisLambers, J. (2009). The importance of niches for the maintenance of species diversity. Nature, 461, 254-257.

Losapio, G., Schöb, C., Staniczenko, P. P. A., Carrara, F., Palamara, G. M., Moraes, C. M. D., Mescher, M. C., Brooker, R. W., Butterfield, B. J., Callaway, R. M., Cavieres, L. A., Kikvidze, Z., Lortie, C. J., Michalet, R., Pugnaire, F. I. \& Bascompte, J. (2021). Network motifs involving both competition and facilitation predict biodiversity in alpine plant communities. Proceedings of the National Academy of Sciences, 118, e2005759118.

May, R. M. (1972). Will a large complex system be stable? Nature, 238, 413-414.

Mayfield, M. M. \& Stouffer, D. B. (2017). Higherorder interactions capture unexplained complexity in diverse communities. Nature Ecology $\&$ Evolution, 1, 0062 . 
Medeiros, L. P., Song, C. \& Saavedra, S. (2021). Merging dynamical and structural indicators to measure resilience in multispecies systems. Journal of Animal Ecology, 90, 2027-2040.

Meerbeek, K. V., Jucker, T. \& Svenning, J.-C. (2021). Unifying the concepts of stability and resilience in ecology. Journal of Ecology, 109, 3114-3132.

Melián, C. J., Bascompte, J., Jordano, P. \& Krivan, V. (2009). Diversity in a complex ecological network with two interaction types. Oikos, 118, 122-130.

Morales-Castilla, I., Matias, M. G., Gravel, D. \& Araújo, M. B. (2015). Inferring biotic interactions from proxies. Trends in Ecology and Evolution, 30, 347-356.

Moreno-Mateos, D., Alberdi, A., Morriën, E., van der Putten, W. H., Rodríguez-Uña, A. \& Montoya, D. (2020). The long-term restoration of ecosystem complexity. Nature Ecology 83 Evolution, 4, 676-685.

Morrison, B. M. L., Brosi, B. J. \& Dirzo, R. (2020). Agricultural intensification drives changes in hybrid network robustness by modifying network structure. Ecology Letters, 23, 359-369.

Mougi, A. \& Kondoh, M. (2012). Diversity of interaction types and ecological community stability. Science, 337, 349-51.

Novella-Fernandez, R., Rodrigo, A., Arnan, X. \& Bosch, J. (2019). Interaction strength in plant-pollinator networks: Are we using the right measure? PLOS ONE, 14, e0225930.

Olesen, J. M., Bascompte, J., Dupont, Y. L., Elberling, H., Rasmussen, C. \& Jordano, P. (2011). Missing and forbidden links in mutualistic networks. Proceedings of the Royal Society B: Biological Sciences, 278, 725732.

Pacini, E. \& Nepi, M. (2007). Nectar production and presentation. In: Nectaries and Nectar (eds. Nicolson, S. W., Nepi, M. \& Pacini, E.). Springer Netherlands. ISBN 978-1-4020-5937-7, pp. 167-214.

Pauw, A. (2013). Can pollination niches facilitate plant coexistence? Trends in Ecology 83 Evolution, 28, 3037.

Pilosof, S., Porter, M. A., Pascual, M. \& Kéfi, S. (2017). The multilayer nature of ecological networks. Nature Ecology \& Evolution, 1, 0101.

Poisot, T. \& Gravel, D. (2014). When is an ecological network complex? connectance drives degree distribution and emerging network properties. PeerJ, 2, e251.

Rohr, R. P., Saavedra, S. \& Bascompte, J. (2014). On the structural stability of mutualistic systems. Science, 345, 1253497-9.

Saavedra, S., Medeiros, L. P. \& AlAdwani, M. (2020). Structural forecasting of species persistence under changing environments. Ecology Letters, 23, 15111521.

Saavedra, S., Rohr, R. P., Bascompte, J., Godoy, O., Kraft, N. J. B. \& Levine, J. M. (2017). A structural approach for understanding multispecies coexistence.
Ecological Monographs, 87, 470-486.

Saavedra, S., Rohr, R. P., Dakos, V. \& Bascompte, J. (2013). Estimating the tolerance of species to the effects of global environmental change. Nature communications, 4, 2350-2350.

Saiz, H., Gómez-Gardeñes, J., Nuche, P., Girón, A., Pueyo, Y. \& Alados, C. L. (2016). Evidence of structural balance in spatial ecological networks. Ecography, 40, 733-741.

Sakavara, A., Tsirtsis, G., Roelke, D. L., Mancy, R. \& Spatharis, S. (2018). Lumpy species coexistence arises robustly in fluctuating resource environments. Proceedings of the National Academy of Sciences, 115, 738-743.

Sauve, A. M. C., Fontaine, C. \& Thébault, E. (2014). Structure-stability relationships in networks combining mutualistic and antagonistic interactions. Oikos, 123, 378-384.

Scheffer, M., van Nes, E. H. \& Vergnon, R. (2018). Toward a unifying theory of biodiversity. Proceedings of the National Academy of Sciences, 115, 639-641.

Seibold, S., Cadotte, M. W., MacIvor, J. S., Thorn, S. \& Müller, J. (2018). The necessity of multitrophic approaches in community ecology. Trends in Ecology 8 Evolution, 33, 754-764.

Simmons, B. I., Wauchope, H. S., Amano, T., Dicks, L. V., Sutherland, W. J. \& Dakos, V. (2020). Estimating the risk of species interaction loss in mutualistic communities. PLOS Biology, 18, e3000843.

Song, C., Altermatt, F., Pearse, I. \& Saavedra, S. (2018a). Structural changes within trophic levels are constrained by within-family assembly rules at lower trophic levels. Ecology Letters, 21, 1221-1228.

Song, C., Rohr, R. P. \& Saavedra, S. (2018b). A guideline to study the feasibility domain of multi-trophic and changing ecological communities. Journal of Theoretical Biology, 450, 30-36.

Thébault, E. \& Fontaine, C. (2010). Stability of ecological communities and the architecture of mutualistic and trophic networks. Science, 329, 853-856.

Thompson, P. L., Rayfield, B. \& Gonzalez, A. (2017). Loss of habitat and connectivity erodes species diversity, ecosystem functioning, and stability in metacommunity networks. Ecography, 40, 98-108.

Vázquez, D. P., Lomáscolo, S. B., Maldonado, M. B., Chacoff, N. P., Dorado, J., Stevani, E. L. \& Vitale, N. L. (2012). The strength of plant-pollinator interactions. Ecology, 93, 719-725.

Vázquez, D. P., Morris, W. F. \& Jordano, P. (2005). Interaction frequency as a surrogate for the total effect of animal mutualists on plants. Ecology Letters, 8, 1088-1094.

Wang, X., Peron, T., Dubbeldam, J. L. A., Kèfi, S. \& Moreno, Y. (2021). Interspecific competition shapes the structural stability of mutualistic networks. arXiv:2102.02259 [physics, q-bio].

Wiegand, T., Wang, X., Anderson-Teixeira, K. J., 
bioRxiv preprint doi: https://doi.org/10.1101/2021.11.29.470335; this version posted November 30, 2021. The copyright holder for this preprint (which was not certified by peer review) is the author/funder, who has granted bioRxiv a license to display the preprint in perpetuity. It is made available under aCC-BY-NC 4.0 International license.

Bourg, N. A., Cao, M., Ci, X., Davies, S. J., Hao, Z., Howe, R. W., Kress, W. J., Lian, J., Li, J., Lin, L., Lin, Y., Ma, K., McShea, W., Mi, X., Su, S.-H., Sun, I.-F., Wolf, A., Ye, W. \& Huth, A. (2021). Consequences of spatial patterns for coexistence in speciesrich plant communities. Nature Ecology 83 Evolution, 5, 965-973.

\section{Data and code availability}

The data and code used to generate the results of this study is available at https://github.com/ garciacallejas/multitrophic_feasibility 
bioRxiv preprint doi: https://doi.org/10.1101/2021.11.29.470335; this version posted November 30, 2021. The copyright holder for this preprint (which was not certified by peer review) is the author/funder, who has granted bioRxiv a license to display the preprint in perpetuity. It is made available under aCC-BY-NC 4.0 International license.

\section{Supplementary Material}

Table S1. Taxa included and number of interactions observed, summed across

plots and years

\begin{tabular}{|c|c|c|c|c|c|c|}
\hline ID & guild & order & family & genus & species & interactions \\
\hline BEMA & plants & Caryophyllales & Amaranthaceae & Beta & macrocarpa & 214 \\
\hline CETE & plants & Gentianales & Gentianaceae & Centaurium & tenuiflorum & 1236 \\
\hline CHFU & plants & Asterales & Asteraceae & Chamaemelum & fuscatum & 1235 \\
\hline CHMI & plants & Asterales & Asteraceae & Chamaemelum & mixtum & 48 \\
\hline HOMA & plants & Poales & Poaceae & Hordeum & marinum & 8093 \\
\hline LEMA & plants & Asterales & Asteraceae & Leontodon & maroccanus & 8656 \\
\hline MESU & plants & Fabales & Fabaceae & Melilotus & sulcatus & 752 \\
\hline PAIN & plants & Poales & Poaceae & Parapholis & incurva & 1006 \\
\hline PLCO & plants & Lamiales & Plantaginaceae & Plantago & coronopus & 46 \\
\hline POMA & plants & Poales & Poaceae & Polypogon & maritimus & 499 \\
\hline POMO & plants & Poales & Poaceae & Polypogon & monspeliensis & 282 \\
\hline PUPA & plants & Asterales & Asteraceae & Pulicaria & paludosa & 677 \\
\hline RAPE & plants & Ranunculales & Ranunculaceae & Ranunculus & peltatus & 18 \\
\hline SASO & plants & Caryophyllales & Amaranthaceae & Salsola & soda & 12 \\
\hline SCLA & plants & Asterales & Asteraceae & Scorzonera & laciniata & 62 \\
\hline SOAS & plants & Asterales & Asteraceae & Sonchus & asper & 241 \\
\hline SPRU & plants & Caryophyllales & Caryophyllaceae & Spergularia & rubra & 69 \\
\hline Anastoechus_spp & pollinators & Diptera & Bombyliidae & Anastoechus & & 43 \\
\hline Andrena_argentata & pollinators & Hymenoptera & Andrenidae & Andrena & argentata & 3 \\
\hline Andrena_cinerea & pollinators & Hymenoptera & Andrenidae & Andrena & cinerea & 56 \\
\hline Andrena_humilis & pollinators & Hymenoptera & Andrenidae & Andrena & humilis & 70 \\
\hline Andrena_spp & pollinators & Hymenoptera & Andrenidae & Andrena & & 54 \\
\hline Bombyliidae & pollinators & Diptera & Bombyliidae & & & 51 \\
\hline Bombylius_major & pollinators & Diptera & Bombyliidae & Bombylius & major & 13 \\
\hline Braconidae & pollinators & Hymenoptera & Braconidae & & & 6 \\
\hline Calliphoridae & pollinators & Diptera & Calliphoridae & & & 16 \\
\hline Chrysididae & pollinators & Hymenoptera & Chrysididae & & & 1 \\
\hline Chrysotoxum_spp & pollinators & Diptera & Syrphidae & Chrysotoxum & & 4 \\
\hline Colias_croceus & pollinators & Lepidoptera & Pieridae & Colias & croceus & 6 \\
\hline Coscinia_spp & pollinators & Lepidoptera & Erebidae & Coscinia & & 6 \\
\hline Culicidae & pollinators & Diptera & Culicidae & & & 1 \\
\hline Cylindromyia_spp & pollinators & Diptera & Tachinidae & Cylindromyia & & 8 \\
\hline Dilophus_spp & pollinators & Diptera & Bibionidae & Dilophus & & 500 \\
\hline Diplazon_spp & pollinators & Hymenoptera & Ichneumonidae & Diplazon & & 1 \\
\hline Empis_spp & pollinators & Diptera & Empididae & Empis & & 2 \\
\hline Empis_tesellata & pollinators & Diptera & Empididae & Empis & tesellata & 21 \\
\hline Episyrphus_balteatus & pollinators & Diptera & Syrphidae & Episyrphus & balteatus & 42 \\
\hline Eristalis_spp & pollinators & Diptera & Syrphidae & Eristalis & & 20 \\
\hline Eucera_spp & pollinators & Hymenoptera & Apidae & Eucera & & 58 \\
\hline Euchloe_crameri & pollinators & Lepidoptera & Pieridae & Euchloe & crameri & 1 \\
\hline Eupeodes_corollae & pollinators & Diptera & Syrphidae & Eupeodes & corollae & 76 \\
\hline Geometridae & pollinators & Lepidoptera & Geometridae & & & 2 \\
\hline Lasiocampa_trifolii & pollinators & Lepidoptera & Lasiocampidae & Lasiocampa & trifolii & 58 \\
\hline Lasioglossum_immunitum & pollinators & Hymenoptera & Halictidae & Lasioglosum & immunitum & 10 \\
\hline Lasioglossum_malachurum & pollinators & Hymenoptera & Halictidae & Lasioglossum & malachurum & 104 \\
\hline Lasioglossum_spp & pollinators & Hymenoptera & Halictidae & Lasioglossum & & 11 \\
\hline Lomatia_spp & pollinators & Diptera & Syrphidae & Lomatia & & 32 \\
\hline Melanopangonius_spp & pollinators & Diptera & Tabanidae & Pangonius & & 1 \\
\hline Melanostoma_spp & pollinators & Diptera & Syrphidae & Melanostoma & & 2 \\
\hline Musca_spp & pollinators & Diptera & Muscidae & Musca & & 166 \\
\hline Nemotelus_spp & pollinators & Diptera & Stratiomyidae & Nemotelus & & 40 \\
\hline Nephrotoma_spp & pollinators & Diptera & Tipulidae & Nephrotoma & & 2 \\
\hline Odontomyia_spp & pollinators & Diptera & Stratiomyidae & Odontomyia & & 21 \\
\hline Osmia_ligurica & pollinators & Hymenoptera & Megachilidae & Osmia & ligurica & 14 \\
\hline Pangonius_spp & pollinators & Diptera & Tabanidae & Pangonius & & 16 \\
\hline Pieris_brassicae & pollinators & Lepidoptera & Pieridae & Pieris & brassicae & 3 \\
\hline Sarcophaga_spp & pollinators & Diptera & Sarcophagidae & Sarcophaga & & 21 \\
\hline Scaeva_spp & pollinators & Diptera & Syrphidae & Scaeva & & 23 \\
\hline Sphaerophoria_scripta & pollinators & Diptera & Syrphidae & Sphaerophoria & scripta & 180 \\
\hline Sphaerophoria_spp & pollinators & Diptera & Syrphidae & Sphaerophoria & & 3 \\
\hline Thymelicus_spp & pollinators & Lepidoptera & Hesperiidae & Thymelicus & & 10 \\
\hline Ulidiidae & pollinators & Diptera & Ulidiidae & & & 216 \\
\hline Vanessa_cardui & pollinators & Lepidoptera & Nymphalidae & Vanessa & cardui & 8 \\
\hline Acrididae & herbivores & Orthoptera & Acrididae & & & 60 \\
\hline Aelia_spp & herbivores & Hemiptera & Pentatomidae & Aelia & & 172 \\
\hline Agriotes_spp & herbivores & Coleoptera & Elateridae & Agriotes & & 77 \\
\hline
\end{tabular}


bioRxiv preprint doi: https://doi.org/10.1101/2021.11.29.470335; this version posted November 30, 2021. The copyright holder for this preprint (which was not certified by peer review) is the author/funder, who has granted bioRxiv a license to display the preprint in perpetuity. It is made available under aCC-BY-NC 4.0 International license.

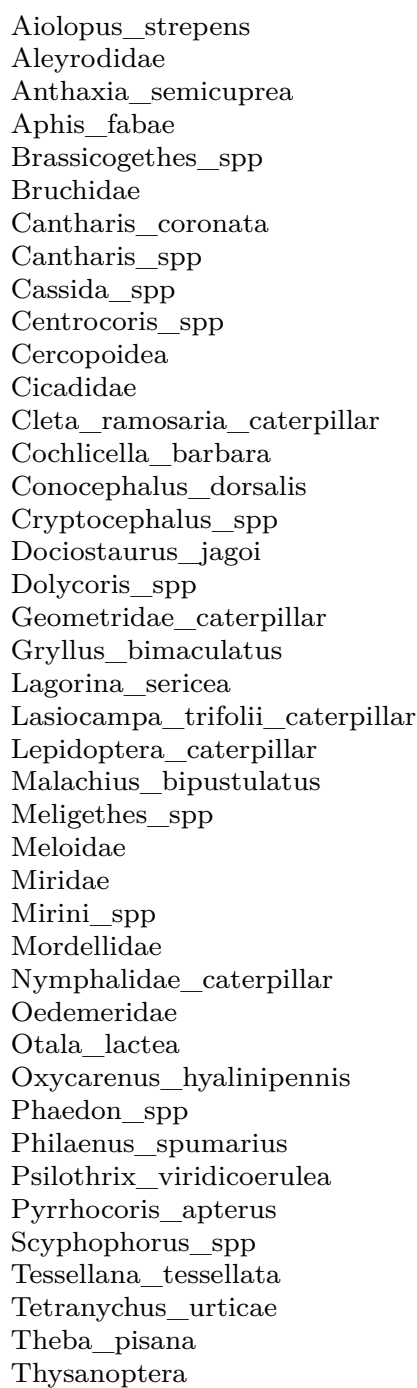

herbivores

herbivores

herbivores

herbivores

herbivores

herbivores

herbivores

herbivores

herbivores

herbivores

herbivores

herbivores

herbivores

herbivores

herbivores

herbivores

herbivores

herbivores

herbivores

herbivores

herbivores

herbivores

herbivores

herbivores

herbivores

herbivores

herbivores

herbivores

herbivores

herbivores

herbivores

herbivores

herbivores

herbivores

herbivores

herbivores

herbivores

herbivores

herbivores

herbivores

herbivores

herbivores
Orthoptera

Hemiptera

Coleoptera

Hemiptera

Coleoptera

Coleoptera

Coleoptera

Coleoptera

Coleoptera

Hemiptera

Hemiptera

Hemiptera

Lepidoptera

Gastropoda

Orthoptera

Coleoptera

Orthoptera

Hemiptera

Lepidoptera

Orthoptera

Coleoptera

Lepidoptera

Lepidoptera

Coleoptera

Coleoptera

Coleoptera

Hemiptera

Hemiptera

Coleoptera

Lepidoptera

Coleoptera

Gastropoda

Hemiptera

Coleoptera

Hemiptera

Coleoptera

Hemiptera

Coleoptera

Orthoptera

Trombidiformes

Gastropoda

Thysanoptera
Acrididae

Aleyrodidae

Buprestidae

Aphididae

Nitidulidae

Bruchidae

Cantharidae

Cantharidae

Chrysomelidae

Coreidae

Cercopoidea

Cicadidae

Geometridae

Geomitridae

Tettigoniidae

Chrysomelidae

Acrididae

Pentatomidae

Geometridae

Gryllidae

Meloidae

Lasiocampidae

Melyridae

Nitidulidae

Meloidae

Miridae

Miridae

Mordellidae

Nymphalidae

Oedemeridae

Helicidae

Lygaeidae

Chrysomelidae

Aphrophoridae

Melyridae

Pyrrhocoridae

Curculionidae

Tettigoniidae

Tetranychidae

Helicidae

$\begin{array}{lll}\text { Aiolopus } & \text { strepens } \\ & & \\ \text { Anthaxia } & \text { semicuprea } & \\ \text { Aphis } & \text { fabae } & 348 \\ \text { Brassicogethes } & & \end{array}$

116

348

3076

$\begin{array}{lll}\text { Cantharis } & \text { coronata } & 5 \\ & & 70\end{array}$

Cantharis $\quad 2$

Cassida

Centrocoris

Cleta

Cochlicella

Conocephalus

Cryptocephalus

Dociostaurus

Dolycoris

Gryllus

Lagorina

Lasiocampa

Malachius

Meligethes

Mirini

Otala

Oxycarenus

Phaedon

Philaenus

Psilothrix

Pyrrhocoris

Scyphophorus

Tessellana

Tetranychus

Theba

urticae

pisana

lactea

hyalinipennis

spumarius

viridicoerulea

apterus 
Network metrics. A main objective of our study was to corroborate the relationship, or lack thereof, between the feasibility domain of complex multi-trophic communities and key network-level properties of ecological communities. In order to do so, we obtained the feasibility domain of each of our 18 field communities and, in parallel, we calculated a series of network-level structural metrics to characterize the observed communities (Table S1] Fig. S1). The comparison of these commonly-used metrics applied to the observed communities and to the two insilico modifications (e.g. mean-field intra-guild interactions and randomized interaction structure, see Methods for more details) reveals fundamental differences among these three structures. First, the connectance of the mean-field communities is, in all cases, consistently higher than the other two communities. Likewise, the complexity of the networks as defined by May's 1972 criterion is also higher in the mean-field communities, which is natural given that this metric includes connectance in its definition. Mean-field communities also display more homogeneous degree distributions than the observed and randomized communities, and counterintuitively, they show no clear trend regarding modularity, with some observed communities showing higher modularity values than the mean-field ones (e.g. herbivores or plant-pollinators ones) and others showing lower modularity (e.g. the full multi-trophic community). Differences between the observed and randomized communities are more subtle, but in general, randomized communities 1) have higher connectance values, 2) are more homogeneous in terms of their degree distribution, and 3) are less modular than the observed communities. The ratio between intra and inter-specific interaction strength is relatively constant across communities and guilds included, with the exception of the observed complete communities (see lower panel of Fig. S1). This is due to the higher number of elements included in the computation of this metric as matrix size increases. In particular, in our study, we assume that herbivores and pollinators do not interact with each other, so that the submatrices $\boldsymbol{\alpha}^{l, h}$ and $\boldsymbol{\alpha}^{h, l}$ of the full community matrix are set to 0 , which decreases the average inter-specific interaction strength, in turn giving a higher absolute value of the average ratio.

To understand the connection between feasibility domain and network-level metrics, we first identified the metrics that better capture the variability from our observed communities. We performed a Principal Component Analysis that resulted in two main axes explaining $73.93 \%$ of the observed variability (Fig. S2 . The first axis obtained is a combination of community richness, May's complexity, and modularity, while connectance, the ratio between intra and inter-specific interaction strength, and the heterogeneity of the degree distribution contribute to both axes.

Based on this analysis, we selected two representative predictors to evaluate their relationship with the feasi- bility domain of our communities: connectance and the heterogeneity of the degree distribution. We selected these two metrics, and not a larger pool of predictor variables, given the logistic limitations to obtain more replicates of our multi-trophic communities, and favouring parsimony and interpretability of statistical models. Connectance has been shown to be a key component of network structure, with underlying correlations with other metrics (Delmas et al., 2018). The heterogeneity of the degree distribution has also been conceptually related to dynamical properties of ecological communities (Carpentier et al., 2021). The degree distribution is mathematically derived from connectance, which means that these two metrics are not independent in theory (Poisot \& Gravel, 2014), but in our case, both metrics are linearly independent in the PCA axes (Fig. S2) and uncorrelated, and we decided to analyze both given their ecological relevance. 
Table S2. Network metrics used for characterizing the structure of the communities sampled. For further details, see the associated code (section "Data and Code availability).

\begin{tabular}{l|l} 
metric & d \\
\hline richness & OV \\
\hline connectance & $S /$
\end{tabular}

definition Overall number of taxa in a community. $S / S p$ : Proportion of links realized in a given interaction matrix $(S)$ with respect to the set of potential links in the community $\left(S_{p}\right)$. Note that $S_{p}$ does not include forbidden links.

intra-specific/inter-specific strength ratio

heterogeneity of the distribution of interaction strengths

modularity

heterogeneity of the degree distribution

May's complexity $\overline{\boldsymbol{\alpha}}_{i, i} / \overline{\boldsymbol{\alpha}}_{i, j}$ : Ratio between mean intra-specific interaction strength $\left(\overline{\boldsymbol{\alpha}}_{i, i}\right)$ and mean inter-specific strength $\left(\overline{\boldsymbol{\alpha}}_{i, j}\right.$, where $\left.\neq \neq j\right)$. Interaction signs are maintained in the calculations.

Quantified as the skewness of the continuous distribution of overall interaction strengths. Interaction signs are maintained in the calculation.

Network modularity, quantified using the algorithm for directed networks by Kim et al. (2010) (see their Eq. (12)). This modified modularity is related to the random walk process in the network, and its value represents the fraction of time spent moving within communities by a random walker minus the expected value of this fraction. Here a community is a group of nodes in which a random walker is more likely to stay.

$G\left(d_{\alpha}\right)$ : Quantified as the Gini index, that provides a unidimensional metric for quantifying heterogeneity in distributions $\left(G(x)=\frac{\sum_{i=1}^{n} \sum_{j=1}^{n}\left|x_{i}-x_{j}\right|}{2 n^{2} \bar{x}}\right)$. The degree of a given interaction matrix $\left(d_{\alpha}\right)$ is the distribution of number of links associated to its nodes.

$\sigma \sqrt{S C}$ : Network complexity as defined in May (1972), where $\sigma$ is the standard deviation of interaction strengths of a given interaction matrix, $S$ its richness, and $C$ its connectance.

\section{Supplementary references}

Kim, Y., Son, S. W., Jeong, H. (2010). Finding communities in directed networks. Physical Review E, 81(1), 016103. 
bioRxiv preprint doi: https://doi.org/10.1101/2021.11.29.470335; this version posted November 30, 2021. The copyright holder for this preprint (which was not certified by peer review) is the author/funder, who has granted bioRxiv a license to display the preprint in perpetuity. It is made available under aCC-BY-NC 4.0 International license.
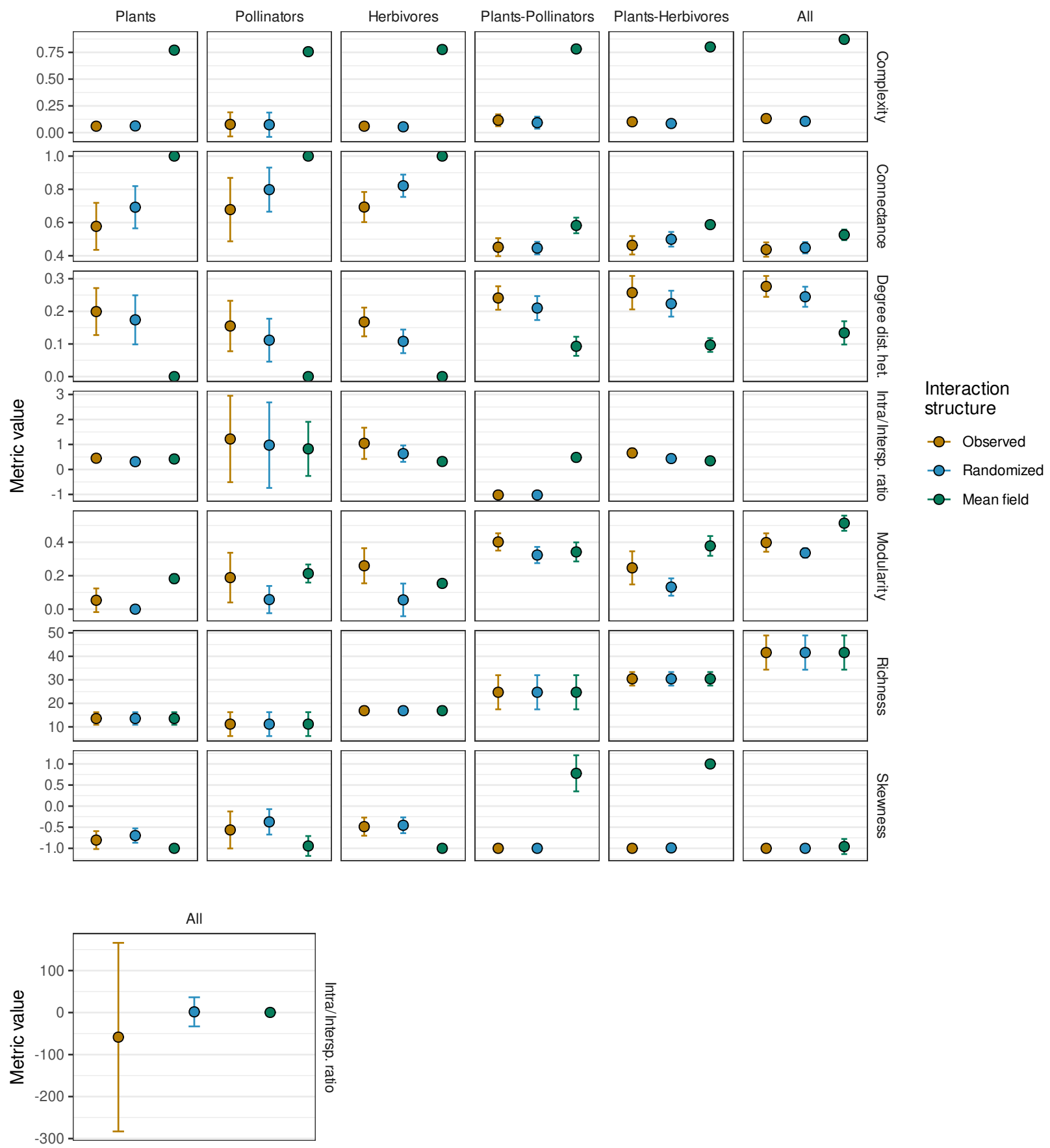

Fig. S1. Network metrics for each community in each plot. We show average values for each metric, obtained from the 18 replicates, and error bars represent the standard deviation of the 18 replicates. For a definition of the metrics used, see Table S1 The ratio between intra-specific and intra-specific interaction strength is bounded between $(0,1)$ in all cases except for the observed complete communities (category all). Given the difference in scale, that panel is shown in the inset below the main plot. 
bioRxiv preprint doi: https://doi.org/10.1101/2021.11.29.470335; this version posted November 30, 2021. The copyright holder for this preprint (which was not certified by peer review) is the author/funder, who has granted bioRxiv a license to display the preprint in perpetuity. It is made available under aCC-BY-NC 4.0 International license.

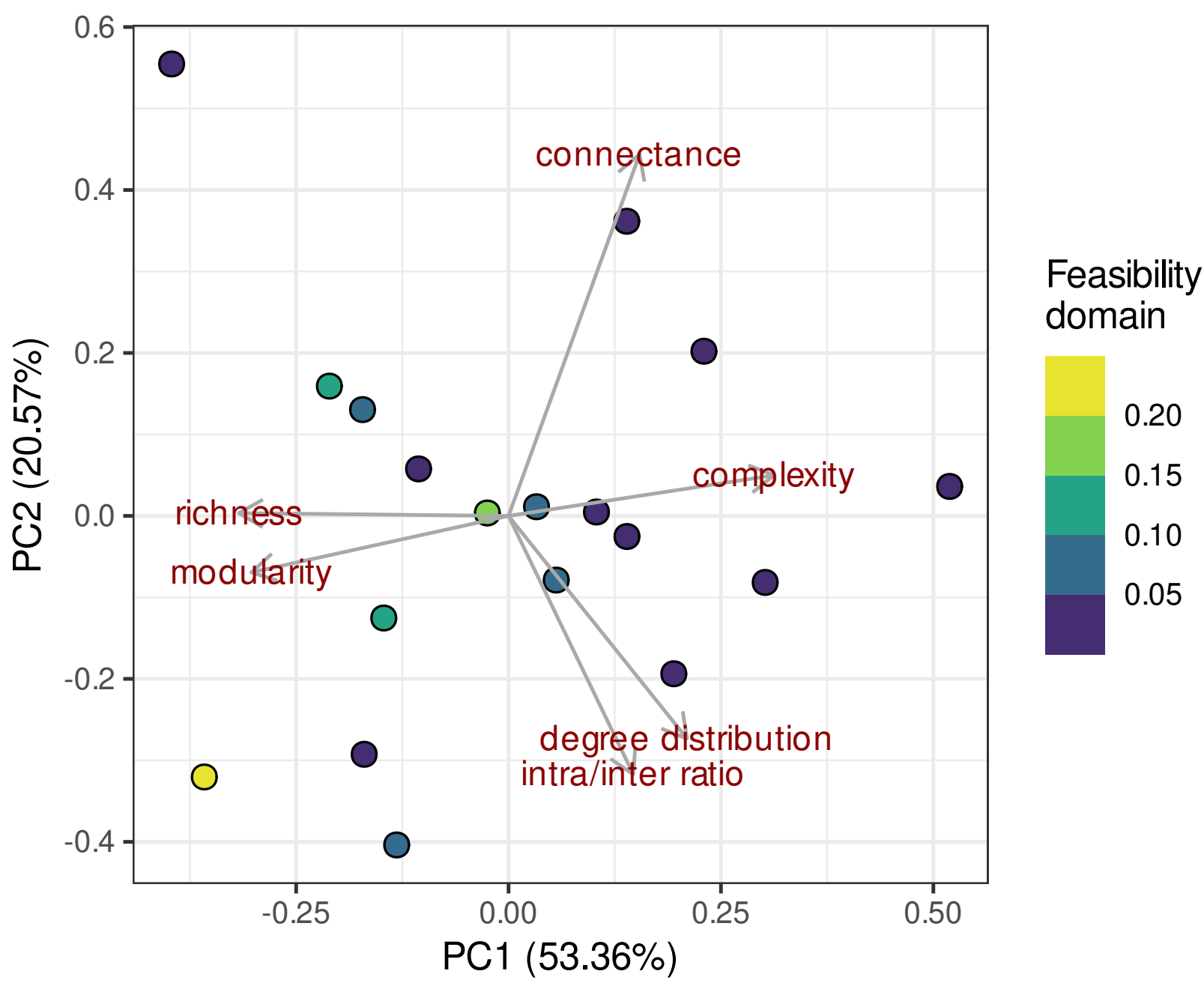

Fig. S2. Principal Component Analysis showing the distribution of the observed communities and the computed network metrics.

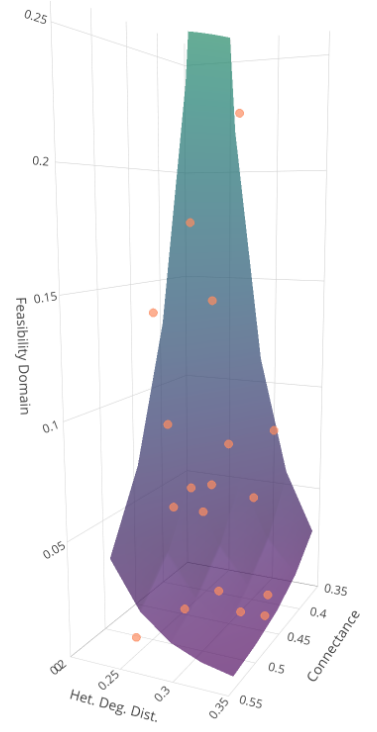

Fig. S3. Feasibility domain, connectance and heterogeneity of the degree distribution of the 18 multi-trophic communities. The surface represents the predictions made by the Generalized Linear Model, with darker shades representing comparatively smaller feasibility domains, and lighter shades representing comparatively higher ones. 